\title{
Deviance in the Internet Use in Working Environment: Key Factors and Remedies based on an Exploratory Study
}

\author{
Borka Jerman Blažič ${ }^{1} \&$ Mateja Gorenc ${ }^{2}$ \\ ${ }^{1}$ Institut Jožef Stefan and University of Ljubljana, Ljubljana, Slovenia \\ ${ }^{2}$ Mateja Gorenc ZPIZ, Ljubljana, Slovenia \\ Correspondence: Borka Jerman Blažič, Institut Jožef Stefan and University of Ljubljana, Ljubljana, Slovenia. \\ E-mail: borka@e5.ijs.si
}

Received: September 26, 2017

Accepted: October 12, 2017 Online Published: November 2, 2017

doi:10.5539/res.v9n4p52

URL: http://doi.org/10.5539/res.v9n4p52

\begin{abstract}
Deviance, in a sociological context, is understood as actions or behaviours that violate social norms, including formally-enacted rules, as well as informal violations of social norms. Deviant behaviour related to Internet was studied mainly as a technology enabling misuse and addiction. In this paper deviant behaviour is studied in the context of two phenomena the addiction to the on-line services and the: abuse in the work place. Both phenomena enact the working forms and cause loss of productivity. As organizations and companies try to minimize the productivity losses resulting from their employees' Internet abuse in work place different approaches are used to solve the problem, some of them like e-surveillance and social control are in conflict with the social norms and the legislation order. The study presented in the paper explores the relationship between a person addicted to the Internet, and the factors that influence the abuse in the workplace. The study results discover whether these two phenomena are the result of the work environment like poor organizational structure in the company or bad human relationships. Another intention of the study was to find out whether the disciplinary measures applied to deter the Internet abuse have effects on the employees behaviour. The study results have shown that the occurrence of Internet abuse in workplace is not strongly related to the work conditions like the bad relationships with co-workers or managers, the missing actions for remuneration or recognition of the good work, and lack of paths for career advancement. The awareness of being e-surveyed by the employer, or being warned with personal messages about the misuse of Internet cause the time spent on the Internet for non-working purposes by the employee to decline. The study was carried out on an exhaustive sample inform an EU member state country where the legislative approach in employee e-surveying differ from other world regions. Managers were involved in this study to light up their everyday practice in deterring the Internet abuse in work place in view of the existing law for employee privacy protection in communication.
\end{abstract}

Keywords: Deviance in Internet use, addiction, abuse, workplace, Internet Acceptable Use Policy, employee privacy, e-surveillance

\section{Introduction}

\subsection{Deviance in Use of Internet}

Deviance, in a sociological context, is understood as actions or behaviours that violate the social norms, including formally-enacted rules, as well as the informal violations of social norms. Deviant behaviour related to Internet was studied in the literature (Harwood, 2014) mainly as a technology enabling deviant behaviour and its use as a new method for enacting older norms. Serious impairments in people lives and their violation of social norms were also reported as a result of their excessive use of on-line services (Morahan, 2005). The impairments related to Internet excessive use include work and interpersonal problems like separation, divorces and exclusion from person domestic social circle. The identified mis-behaviour is mostly labelled as Internet addiction. The concept of addiction is still traditionally used to describe a physical dependence, but it is also labelled as disorder and misbehaviour (Holden, 2001; Kayiş, 2016). In the literature a variety of terms can be found introduced by academics in attempts to define the phenomenon of "Internet addiction" (Harwood, 2014; Young, 1998). Some of them describe the occurrence of this behaviour as "pathological Internet use" (Neging, 2014) or "problematic Internet use" (Noll, 2013). However, most of them agree that Internet addiction represents a syndrome of intense and long-lasting preoccupation with using Internet services ( $\mathrm{Li}, 2016$; Treuer, 2001). Addicted people have the 
feeling that the world outside the Internet is boring and that their social interaction with "real" people is decreased and low (Noll, 2013). Feelings of loneliness are also indicated, and depression is often diagnosed (Gorenc, 2016). The bulk of the work in the area of defining Internet addiction has been undertaken by Young and Case as early as 1998, Young proposed a set of criteria for diagnosing Internet addiction based on the DSM-IV of American Psychiatric Association (APA, 1994) criteria for pathological gambling (Young, 1998). She selected 8 of the 10 criteria used to define gambling addiction, which she felt are the most appropriate to identify a preoccupation with the Internet and the need for increased time spent online to achieve the same amount of satisfaction as with gambling (Shaffer, 1996).

\subsection{Internet Addiction and Internet Abuse}

The existence of depression symptoms or mood changes due to Internet use was found to be limited, but obvious evidence was found to apply to persons that stay online much longer than anticipated, and to jeopardise their job or relationships due to the excessive use of the Internet. The latter is considered as Internet abuse within working environment. According to Young person fulfilling five out of the eight criteria are considered as Internet-dependent or addicted. In Young's original study of Internet addiction (Young, 1996), approximately one half of the Internet-dependent individuals reported were found to have suffered severe work or school-related problems because they spent too much of their working time with Internet services. In that context they are considered to abuse their duties due to the diagnosed Internet addiction. Deviant use of the Internet in the workplace, which is usually described as personal use of the services provided by an Internet network within the work environment and as an abuse was approached in 2008 by few authors (Chen, 2008). It was considered that the abuse happen when an employee voluntary use Internet services during working hours using company resources outside of his/her customary job/work requirements. Later, Griffiths (Griffiths, 2010) revealed in his study that office workers abuse the Internet by spending most of the time on the Internet during their working hours for booking holidays, shopping online, sending e-mail or chatting with friends. His study was based on the data published by the International Data Corporation pointing to employees' attitudes that have access to Internet in their work places. The study reported that 90 per cent of employees felt that the Internet can be addictive, and 41 per cent admitted that they spent at least 3 hours per week for personal Internet surfing at work, mainly for web browsing and shopping.

\subsection{The Internet Deviance Problem and the Literature Study}

Internet abuse and Internet addiction are related, but they are not the same (Shapira, 2000). The problem of Internet addiction has attracted academics and researchers after the extensive integration of online services into the everyday lives of people mainly by the end of the century in most developed countries with large populations and a high economic power. The definitions of Internet addiction and factors that influence the phenomenon were developed further based on studies carried out in the USA, China, the UK, South Africa, Taiwan and Australia (Li, 2014; Jiang, 2014). Most of these study findings were derived from samples with student population at universities or high schools (Selwyn, 2008), but academic staff was included as well (Chang, 2008). The employee's population regarding Internet abuse is seldom studied in the literature. In addition, no studies are known to be carried out in other countries or among other user populations where the affordability of Internet technology and population attitudes differs. There, the cost of online services, the working climate, the work environment and the legislation regarding personal privacy protection in communication are factors that also influence Internet addiction and the frequency of occurrence of Internet abuse in the workplace. In that context, the employees' behaviour and attitudes towards policies undertaken to deter the abuse could be different as well. Studies in that context are missing. It should be noticed here that abuse in the workplace does not necessarily have negative effects on the addicted users themselves, with the exception of a decrease of their productivity. In contrast, the organization or the company where these people work may suffer. With the proliferation of Internet services at work and the appearance of the Internet abuse, organizations and companies have attempted to minimize the productivity losses resulting from their employees' attitudes. The approaches applied may also differ from country to country or region as well between different organizations. However, the current known studies are limited.

\subsection{The Exploratory Study Approach}

This paper tries to contribute further in this area by presenting the findings of an exploratory study among the working population of Slovenia in contrast to the published studies about addiction and abuse carried among students and academic sphere in large countries outside Europe. The study involves participation of employees from different sectors and face to face interviews with HR and IT managers of the involved institutions. The study was designed to search for factors and their antecedents relating to Internet abuse in the workplace and the 
change in the employees' behaviour after the employer attempts to deter the Internet abuse with different measures. In that context the study brings new findings and new results as both perspective were considered in the research design: the employees and the managers' approaches to treat this phenomenon. The study examined and tested known instruments for internet-addiction diagnosis, developed in previous studies of this subject, like IAT (Young, 2004) to confirm the presence of Internet addiction and its associated factors, but the abuse factors and the employer's approach are new and studied from different point of view. This approach was expected to bring valuable input for preparation of recommendation for deterring the Internet abuse and for protecting the employee's productivity. Slovenia is a member of the European Union from 2004 and has a well-developed economy where the Internet is used in business and other work processes like production automatization. The use of Internet services among the Slovenian population is high and is close to 80 per cent of the population. However, the Internet abuse in the workplace was not yet studied, most probably due to the existing legacy principles and the organizational climate within the Slovenian enterprises that reflect the remains of the socialist country economy. It was supposed also, that the factors influencing the abuse may be different from some identified in the literature. The same applies to the disciplinary actions used. Important point in the study was the existing awareness among the employers about the implementation of the European legislation regarding privacy protection of employee's electronic communication. All these aspects were considered in the survey questionnaire and in the formulation of the hypotheses. The obtained study results presented in the paper bring a new view on both phenomena, the Internet addiction and abuse in work place as well about the approach of the Slovenian managers in applying disciplinary measures to deter the abuse. The findings based on data collected were used to approve or reject the research hypotheses and to construct a model that graphically presents the dependencies between the factors of the abuse and addiction. The face-to-face interviews with the managers and their replies were used for formulating the recommendations for a better and more successful approach in deterring Internet abuse. The paper is organized in seven sections. The introduction is followed by the study background. The research design and hypotheses section describes the applied approach. The research design section is then followed by the description of the used methodology. The presentation of the results section is followed by discussion and presentation of the study limitations. The paper ends with the conclusion section.

\section{Research Design and Research Hypotheses}

\subsection{Background and the Study Objectives}

The rise of the number of Internet-addicted people contributed to the employers' concerns about the productivity and atmosphere in affected companies. According to the survey of human-resource directors in the USA reported by Young (Young, 2004) approximately $70 \%$ of US companies provide Internet access to over one half of their employees, and statistics show that employee Internet abuse is still on the rise. In a survey performed on 1439 workers by Vault.com, $37 \%$ of the employees admitted that they surf constantly at work, $32 \%$ surfed a few times a day, and $21 \%$ surfed a few times a week. In a survey of 224 corporations by Websense, Inc., an electronic monitoring company (Websense Inc., 2000), 64\% of the companies have taken disciplinary actions against employees, and more than $30 \%$ of them have terminated an employee's job due to the inappropriate use of the Internet (Snapshot Spy, 2008). Specifically, the sacking of employees was the result of accessing pornography $(42 \%)$, online chatting $(13 \%)$, gaming $(12 \%)$, sports $(8 \%)$, investing $(7 \%)$ and shopping $(7 \%)$. Led by this finding, this study was designed to examine the situation an EU Member State, consideredas a moderately developed Central European country, ranking $17^{\text {th }}$ in the EU in terms of digitalization of the country's economy (Internet at Europe, 2014). The study is the first one to investigate Internet addiction and abuse in the workplace in a larger region of Central and Western Europe. As the this type of deviance is treated with different disciplinary measure such as employee e-monitoring at the workplace or job termination, the practice of the managers was designed to be studied in view of the European legislation on privacy protection in communications, and the use of tools that jeopardize the privacy. It is worth noting here that when it comes to the privacy of personal communications and data, the United States (Staples, 1997) and Europe have very different concepts. Europe has a basic set of legal protection mechanisms for personal privacy which cannot be found in the United States (Rustad, 2005). In the USA, employees have no reasonable expectation of privacy when using corporate Internet facilities (Staples, 2013) while in the EU privacy protection is based on several directives addressing employment law, data protection and telecommunications legislation. In Slovenia as in other European countries, for example, employees have a right to on-line privacy in the workplace. This approach became clear some years ago when the French courts, e.g., the Supreme Court, ruled that employers do not have the right to read an employee's e-mails or capture other electronic records communicated over the Internet. A similar situation happened in Slovenia in the case of the e-mail exchange of an employee at the Ministry of Foreign affairs. The court ruled in favour of the employee privacy protection. In the context of the 
adopted legislation, the study was designed to provide an insight into the practices applied by the majority of the interviewed managers. The examined factors that may impact the Internet abuse in the workplace were formulated to be either result of a poor organizational structure in the company, bad relationships in the work environment, lack of remuneration and the presence of company Acceptable Use Policy (AUP) for Internet. The study was shaped in a way that enables identification of the correlations between the companies' rules about Internet use and the extent of an employee's behaviour. The ratio between the time spent on the Internet for business and private purposes and the potential impact of demographic, social and the region were the employees were employed were explored in terms of their influence on the appearance of Internet abuse. The intention of the study was also to find out whether applied disciplinary actions have an impact on the employee's behaviour towards positive changes regarding the time spent on the Internet for private purposes. How employees react to the information that they are monitored in the workplace was another question to be answered by the study, as well as whether the Internet abuse decreases with the introduction of electronic surveillance. The final aim of the study was to create a structural model that visually presents the relationships and the impact factors found to influence the addiction and the abuse. The results were intended to draw the basic rules and approaches for assisting companies and organizations in implementing effective initiatives for improving the employee Internet management practices without violating the data-privacy protection laws as a fundamental right enjoyed by European workers.

\subsection{Research Design and Research Hypotheses}

Internet abuse in the workplace is understood as conducting non-work-related activities or public communications online during working hours within the company and on equipment belonging to the company. Internet abuse in the workplace is also defined as the misuse of information technology belonging to the organization for achieving personal gains, instead of the goals of the organization (Chen, 2008). This is considered as violation of the normal working norms in any kind of organization, company or institution. This misuse is supposed to be correlated to a person who most probably displays Internet addiction, where the diagnosis of this addiction is usually made using the criteria developed by the American Psychiatric Association (APA, 1994). According to the APA, the individual needs to show a persistent presence of at least four out of eight criteria over a 12-monthperiod in order to be qualified as an Internet addict. An employee abusing the Internet will be most probably be distracted from its usual workload as is engaged in unproductive or unethical activities. These Internet related activities range from online shopping, chatting with friends or family, playing games, on-line gambling, sports betting or watching pornography (Chen, 2008). Sometimes it may lead to non-ethical use like malware application or purchase of illegal substances.

The questions designed for the study were grouped into two classes: one group of questions addressed the key factors that predicted Internet addiction based on non-work related factors, i.e., person's internal causes and the second group of questions that was expected to predict the key factors that influence the appearance of Internet abuse based on work-related issues such as the climate in the working environment, poor internal relationships at the workplace, the influence of the company's applied disciplinary actions, such as electronic surveillance for monitoring Internet use or blocking and filtering Internet content, and the employee's perception about the need to follow company AUP at work. In that context, any insight into employee communications without his/her consent abuse according to European law is treated as privacy abuse. The question addressing the use of such tools was included in the employee's survey. Managers were asked about their views and approach taken in practice when e-surveillance is applied or is planned to be applied. The first group of hypotheses was used to validate the employee's internal causes of addiction that usually lead to Internet abuse. In that context the locus of self-control and self-esteem were questioned with questions addressing like addiction to gambling or sports betting. Short-term comfort, excitement, and distraction are the properties that also may influence the person to become addicted. So, prior person's experience with the comfort and the degree of gratification from non-habitual use of Internet were also considered to contribute to loss of internal self-control. Other factors that were supposed to influence a person to become addicted were his/her escape from the real world, the feelings of loneliness or low personal social acceptability, missing personal messages or calls from friends or family and were also included in the survey questionnaire. Contrary to these factors, individuals with a higher degree of internally-controlled orientation usually show more eagerness and curiosity, and less anxiety when using the virtual world and online communication. These individuals have a greater restraint in their Internet use, without displaying behaviour related to restlessness, loneliness and depression (Chak, 2004). With the same logic, an individual with a higher degree of internal local focus of control is more likely to control the use of Internet activities without experiencing deviances typical for Internet addiction. Other factors that were supposed to lead to Internet abuse and are not related to personal feelings were expected to be related to the environment of the 
workplace. So, the second group of questions were based on questioning issues such as relations to the co-workers, organization of the work environment in the company, relations with the managers, the appropriateness of the salary and remuneration nor recognition of employee good work. The duration of the working hours was another element included in the survey questionnaire. Career building and possibilities of additional education and training provided within the company were the other factors that were expected to shape the company atmosphere and influence the phenomenon of Internet abuse. Eight hypotheses were set up to enabled the diagnosis of Internet addiction among the included employees. They are listed below. The last hypothesis from this group contains two sub-hypotheses.

H1: There is a correlation between the addiction to computer games and Internet addiction.

$\mathrm{H} 2$ : There is a correlation between the addiction to social networks and Internet addiction.

H3: There is a correlation between selecting always a holiday location with on-line access (having always access to the Internet) and Internet addiction.

H4: There is a correlation between the addiction to the virtual world and Internet addiction.

H5: There is a correlation between the addiction to online shopping and Internet addiction.

H6: There is a correlation between the addiction to pornography and Internet addiction.

$\mathrm{H7}$ : There is a correlation between the addiction to sports betting and gambling, and Internet addiction.

H8a: There is a correlation between feelings of loneliness and Internet addiction.

H8b: There is a correlation between feelings of being excluded from the real social environment, and Internet addiction.

The second group of hypotheses, $\mathrm{H} 1$ to $\mathrm{H} 4$, where $\mathrm{H} 1$ contained two sub-hypotheses, were formulated to evaluate the factors that may have an impact on Internet abuse in the workplace. They were defined as follows:

The climate within the company environment that influences the occurrence of Internet abuse in the workplace was composed from three sub-hypotheses:

H1a1: The remuneration and career possibilities within the company contribute to Internet abuse in the workplace.

H1a2: Dissatisfaction with the work has an impact on the occurrence of Internet abuse in the workplace.

H1b: Poor relationships within the organization contribute to Internet abuse in the workplace.

$\mathrm{H} 2$ : There is a connection between addiction to the Internet and Internet abuse in the workplace.

H3: The abuse of working hours when using the Internet for private purposes in the workplace will be reduced if a specific company Internet use policy is applied.

H4: Employees will be willing to reduce Internet abuse in the workplace if they are aware that e-surveillance mechanisms are in place.

The hypotheses designed to evaluate the managers' approach to Internet abuse factors and the uses of disciplinary measures were formulated as follows:

H1: The lack of an Internet Acceptable Use Policy is related to the introduction of more severe disciplinary measures.

$\mathrm{H} 2$ : The provision of additional education for employees has a positive correlation to the deterrence of Internet abuse.

H3: The introduction of e-monitoring increases the fear among employees that stricter disciplinary measures will be introduced.

To test the hypotheses, across-sectorial survey-based approach was used for collecting data and the subsequent analysis of the data. For each of the presented hypotheses, several possible answers (from 12 to 6, depending on the question) were available to the responders, with an additional option to freely formulate an answer. For some of the hypotheses, the possible answers contained scales from 1 to 5 according to Licker satisfaction survey scale. 


\section{Method}

\subsection{Data Collection}

The research conducted and presented in this paper is exploratory and deductive at the same time. The quantitative research involved 1651 people, out of which 599 responded by filling out the online survey; 448 questionnaires were found to be valid, while 151 questionnaires were invalid, so the final sample consisted of $\mathrm{N}=448$. The responders were employees in the Republic of Slovenia, aged 18 to 65 , who use a computer at work and have an Internet connection. The quantitative survey took place from 30.6.2015 to 1.8.2016. The sample demographic and other variables like job sector, organization size and region where the organization is located are presented in Table 1.

Table 1. Demographic variables of the employee sample

\begin{tabular}{|c|c|}
\hline Demographic variables & Sample $(N=448)$ \\
\hline \multicolumn{2}{|l|}{ Sex } \\
\hline Female & $45.5 \%$ \\
\hline Male & $54.5 \%$ \\
\hline \multicolumn{2}{|l|}{ Age (years) } \\
\hline below 30 & $8.5 \%$ \\
\hline $30-40$ & $31.0 \%$ \\
\hline $40-50$ & $36.6 \%$ \\
\hline 50 or above & $23.8 \%$ \\
\hline \multicolumn{2}{|l|}{ Education } \\
\hline secondary School (V) or less & $20.3 \%$ \\
\hline college (VI) & $12.5 \%$ \\
\hline university, college, academy of arts (VII) & $48.0 \%$ \\
\hline specialization or Master's degree (VII/2) & $19.2 \%$ \\
\hline \multicolumn{2}{|l|}{ Income } \\
\hline up to EUR 1,000 & $32.1 \%$ \\
\hline EUR 1,000 to 2,000 & $55.4 \%$ \\
\hline EUR 2,000 to 3,000 & $8.3 \%$ \\
\hline over EUR 3,000 & $3.1 \%$ \\
\hline no answer was provided & $1.1 \%$ \\
\hline \multicolumn{2}{|l|}{ Job Sector } \\
\hline public sector & $50.7 \%$ \\
\hline private sector & $49.3 \%$ \\
\hline \multicolumn{2}{|l|}{ Organization Size } \\
\hline micro or small organization & $23.7 \%$ \\
\hline medium-sized organization & $31.1 \%$ \\
\hline large organization & $45.2 \%$ \\
\hline \multicolumn{2}{|l|}{ Region } \\
\hline East & $45.8 \%$ \\
\hline Central & $33.9 \%$ \\
\hline West & $20.3 \%$ \\
\hline
\end{tabular}


Another quantitative research was conducted with the managers, i.e., heads of the IT departments or HR managers from 274 enterprises, where the employees use computers at work. 103 of them sent answers to the e-survey questions, out of which 11 were invalid, so the sample consisted of $\mathrm{N}=91$. Most of them agreed to participate in the face-to-face interviews organized within the focus group. The questionnaire for the e-survey for managers is presented in the Appendix; the demographic and other information from the manager sample are presented in Table 2.

Table 2. Sample structure for the manager survey

\begin{tabular}{lc}
\hline Basic data & Sample (N=91) \\
\hline Type of the organization & $13.3 \%$ \\
joint-stock company & $58.9 \%$ \\
limited-liability company & $18.8 \%$ \\
public organization/institution & $3.3 \%$ \\
SME & $3.6 \%$ \\
corporation & $3.1 \%$ \\
legal body & \\
Number of employees & $56,7 \%$ \\
up to 50 & $13.3 \%$ \\
from 50 to 250 & $16.7 \%$ \\
from 250 to 1000 & $13.3 \%$ \\
over 1000 & \\
Type of sector & $15.6 \%$ \\
Public & $84.4 \%$ \\
private & \\
Region & $31.1 \%$ \\
east & $40.0 \%$ \\
central & $28.9 \%$ \\
west &
\end{tabular}

The manager e-survey included 23 questions formulated in a way that addresses the main research questions. Later, interviews were organized with a group of 31 managers in three consecutive terms, each time with a different group of managers. The division of the main employee sample into several groups displayed sufficiently similar structures of the groups to the structure of the whole sample. The survey questions were designed to be simple but detailed. The focus group model (Kitzinger, 1999) was applied for carrying out the interviews with the managers, as it enabled a way to collect data based on the group member's interactions. The calculation of reliability of both sample and the items analysis were used as methods to confirm or reject the reliability of the questionnaire's (Churchill, 2004). The calculated Cronbach alpha coefficient indicated a solid general reliability among the variables, as the index value was between 0.7 and 0.9 . Only one employee claim was removed due to its low index value. This was the following: "I can surf the Internet without being disturbed at my workplace". The items related to gambling or sports betting were also removed as the number of received answers was very low. ANOVA tests for studying the variance and a factor analysis for removing the correlated variables were performed as well. The PAF (Principle Axis Factoring) showed that the addiction to computer games, displayed the highest weight. The next highest factor associated with Internet addiction was the addiction to social networks. The PAF analysis pointed out that three variables out of 13 have a major influence on addiction with the following consequences: the "appearance of undesirable effects in everyday life", "dependence to and living in the virtual world" and "strong dependence on the social networks activity". The major factor found in the category of online shopping was the "occurrence of unplanned excessive use of money for online shopping". In the case of pornography, the major factor out of the 10 offered was "masturbation when 
watching pornography". The loneliness group of variables gave two dominating factors: "exclusion from the social environment, and the feeling of being alone". The PAF analysis of the climate in the organization, either in case of an enterprise or a public institution, has shown two major factors that correlated with most of the other studied items (44 of them): "satisfaction with the organizational climate" and "the existence of real chances for advancement in the employees' careers". The issue of e-monitoring has shown that the dominating factor was: "potential disciplinary measures were applied after the employee's misuse was discovered by means of e-monitoring tools". The factor dominating Internet abuse at the workplace was "the existence of Internet addiction". The selected independent variables were used to verify the hypotheses.

\subsection{Data Analysis}

A statistical analysis was performed by measuring the mean value and the highest achieved score among the answers received. The 151 questions in the survey were divided into four major groups, starting with questions addressing the use of Internet in the workplace and the existence of measures that control Internet use for private and personal purposes. The questions addressing the application of disciplinary measures offered several possible answers, but the most frequent answer was "the readiness of the employees to change their attitudes regarding the misuse of Internet occurs only in the case of being aware that an e-monitoring system is applied at their workplace". The next group of ten questions addressed the reason that drives the misuse; the answer that got the highest number of positive answers was the one that read: "I need to relax on the Internet". As possible reasons for Internet misuse, the answers that got the next highest scores were "I use the Internet as a method to escape from the boring work", "I use the Internet due to the bad relationships in the workplace", "I use Internet because of lack of managerial control" and "because I am under a lot of pressure at the workplace". Internet addiction was addressed with questions that allowed the employees to provide information about the time they spend either on the Internet or on their mobile phone (with Internet access). The addiction was investigated through questions about the dependence on computer games, social networks, online shopping, pornography, gambling or sports betting. The answers resulted in moderate scores, with the highest score being given to the dependence on social networks. Most of the employees also answered that they would never choose a holiday location without access to the Internet meaning that they need an access to the Internet all the time in their life. The only exception in this group of questions was sports betting and gambling, which brought the lowest score and was removed from further consideration. In the group of questions addressing loneliness, the highest score was obtained for the answer "I feel miserable and lonely when I work". The influence of the climate at the workplace was studied by means of 12 questions, and each of them allowed 5 possible answers with 5 possible scores from 1 to 5 of the Likert scale. The employees were asked whether the quality of the performed work and the amount of work is positively recognized within the company, whether they are rewarded in accordance with their efforts at work, and whether the remuneration, if applied, matches the quality of the work presented. Other questions addressed the internal relationships and communications among the employees themselves and with the managers, the labour organization, and whether the employee's motivation for advancement is encouraged or whether acquiring new knowledge is promoted within the company. Work satisfaction was tested with questions addressing the salary, the work environment, the working schedule, and the type of employment offered. The employees were also asked about the existing Internet use controls, that were defined as no control at all, or filtering and blocking content or sites or services on the computers they use. Some employees answered that they have signed a declaration that they will use the Internet for work-related purposes only, and some have answered that they have received messages when they logged into the company computer-with a content informing the employee about the correct use of Internet in the workplace. The answer "severe disciplinary measures, like firing the employee or lowering his/her salary due to Internet abuse, are applied" got a low score. Most of the received answers about the satisfaction in the organization provided mostly positive answers, the highest number of positive answers was given to the following statement: "the satisfaction with the work schedule is acceptable"; the lowest number of positive answers was given to the questions addressing salaries, the remuneration and the possibility for advancement. The amount of misuse of the Internet was measured with the average number of hours per week spent on the Internet for purposes not related to the work for the company. This ranged from 1 to 3 hours and more.

\subsection{Evaluation of the Hypotheses}

The basis for the understanding of the interactions between the variables was the determination of correlations among independent and dependent variables that followed from the results of the regression analysis. Tables 3 and 4 present the values of the t-statistics and the regression coefficient. The parameter "p" allowed confirmation or rejection of the suggested hypotheses. 
Table 3. Verification of the hypotheses of Internet addiction- $-\mathrm{t}$-statistics and regression coefficients

\begin{tabular}{|c|c|c|c|c|c|c|}
\hline Dependent Variable & Independent Variable & $\mathbf{R}^{2}$ & OR & $(95 \% \mathrm{CI})$ & $\mathbf{t}$ & $\mathbf{p}$ \\
\hline $\begin{array}{c}\text { Internet addiction } \\
\text { H1 confirmed }\end{array}$ & Addiction to computer games & 0.455 & 0.675 & $(0.611 ; 0.749)$ & 19.300 & 0.000 \\
\hline $\begin{array}{l}\text { Internet addiction } \\
\text { H2 confirmed }\end{array}$ & Addiction to social networks & 0.366 & 0.605 & $(0.556 ; 0.712)$ & 16.034 & 0.000 \\
\hline $\begin{array}{c}\text { Internet addiction } \\
\text { H3 confirmed }\end{array}$ & $\begin{array}{l}\text { Addiction to always have access } \\
\text { to Internet }\end{array}$ & 0.225 & 0.474 & $(0.425 ; 0.603)$ & 11.381 & 0.000 \\
\hline $\begin{array}{l}\text { Internet addiction } \\
\text { H4 confirmed }\end{array}$ & Addiction to the virtual world & 0.127 & 0.356 & $(0.298 ; 0.490)$ & 8.042 & 0.000 \\
\hline $\begin{array}{l}\text { Internet addiction } \\
\text { H5 confirmed }\end{array}$ & Addiction to online shopping & 0.269 & 0.519 & $(0.448 ; 0.610)$ & 12.822 & 0.000 \\
\hline $\begin{array}{l}\text { Internet addiction } \\
\mathrm{H} 6 \text { confirmed }\end{array}$ & $\begin{array}{l}\text { Addiction to pornographic } \\
\text { contents }\end{array}$ & 0.372 & 0.610 & $(0.545 ; 0.695)$ & 16.261 & 0.000 \\
\hline $\begin{array}{c}\text { Internet addiction } \\
\text { H7 rejected due to low } \\
\text { feedback }\end{array}$ & $\begin{array}{l}\text { Addiction to sports betting and } \\
\text { gambling }\end{array}$ & - & - & - & - & - \\
\hline $\begin{array}{l}\text { Internet addiction } \\
\text { H8a confirmed }\end{array}$ & Feelings of loneliness & 0.040 & 0.201 & $(0.003 ; 0.666)$ & 2.000 & 0.048 \\
\hline $\begin{array}{l}\text { Internet addiction } \\
\text { H8b confirmed }\end{array}$ & $\begin{array}{c}\text { Exclusion from the social } \\
\text { environment }\end{array}$ & 0.059 & 0.242 & $(0.075 ; 0.737)$ & 2.433 & 0.000 \\
\hline
\end{tabular}

The results in Table 3 show that the greatest impact on the internet addiction spring up is related to the addiction with computer games (it was found linear, positive and medium correlation), then addiction to pornography (linear, positive and medium correlation), addiction to social networks (linear, positive and medium correlation), addiction to online shopping (linear, positive and medium correlation), the effects of addiction to social networks (linear, positive and medium correlation), addiction to virtual communication and virtual world (linear, positive and mean correlation), isolation or feeling loneliness (exclusion from the environment) (linear, positive and mean correlation). The results are similar to previous findings (Jiang, 2014), however some differences are noticeable, e.g., the feeling of loneliness and exclusion of the environment did not correlated to the Internet addiction as high as in the Jiang study. Slovenian do not have the same level of loneliness as the people in the Jiang study (Jiang, 2014). Hypothesis H8 that addressed loneliness did not correlated as expected, however the parameter $\mathrm{p}$ was sufficiently low the hypothesis to be confirmed The hypotheses of the first group were all confirmed with exception of Hypothesis $\mathrm{H} 7$ that addresses sports betting and gambling. The other group of hypotheses was evaluated with the statistical results and the regression coefficient $\mathrm{p}$ obtained from elaboration of the Internet abuse data in work place. It appeared that the electronic monitoring has the strongest influence on the level of Internet abuse in the workplace (linear, positive and very strong correlation). The employees will reduce the time spent on the Internet for private purposes if they are aware of the use of e-surveillance tools and are e-monitored by the company managers.

Table 4. Verification of the hypotheses of Internet abuse - $\mathrm{t}$-statistics and regression coefficients

\begin{tabular}{|c|c|c|c|c|c|c|}
\hline Dependent Variable & Independent Variable & $\mathbf{R}^{2}$ & OR & $(95 \% \mathrm{CI})$ & $\mathbf{t}$ & $\mathbf{p}$ \\
\hline $\begin{array}{l}\text { Internet abuse in the } \\
\text { workplace }\end{array}$ & $\begin{array}{l}\text { Organizational climate- } \\
\text { Remuneration and career }\end{array}$ & 0.001 & -0.024 & $(-0.110 ; 0.065)$ & -0.502 & 0.616 \\
\hline H1a1 rejected & development & & & & & \\
\hline
\end{tabular}




\begin{tabular}{|c|c|c|c|c|c|c|}
\hline $\begin{array}{c}\text { Internet abuse in the } \\
\text { workplace } \\
\text { H1a2 rejected }\end{array}$ & $\begin{array}{c}\text { Organizational climate- } \\
\text { satisfaction }\end{array}$ & 0.007 & -0.085 & $(-0.171 ; 0.008)$ & -1.791 & 0.074 \\
\hline $\begin{array}{l}\text { Internet abuse in the } \\
\text { workplace } \\
\text { H1b rejected }\end{array}$ & $\begin{array}{c}\text { Relations in the } \\
\text { organization }\end{array}$ & 0.005 & -0.071 & $(-0.153 ; 0.021)$ & -1.501 & 0.134 \\
\hline $\begin{array}{l}\text { Internet abuse in } \\
\text { the workplace } \\
\text { H2 confirmed }\end{array}$ & Internet addiction & 0.142 & 0.377 & $(0.268 ; 0.426)$ & 8.607 & 0.000 \\
\hline $\begin{array}{c}\text { Internet abuse in the } \\
\text { workplace } \\
\text { H3 rejected }\end{array}$ & $\begin{array}{l}\text { Company } \\
\text { Internet use policy }\end{array}$ & 0.000 & 0.020 & $(-0.072 ; 0.110)$ & 0.416 & 0.678 \\
\hline $\begin{array}{l}\text { Internet abuse in } \\
\text { the workplace } \\
\text { H4 confirmed }\end{array}$ & $\begin{array}{c}\text { Electronic } \\
\text { e-surveillance }\end{array}$ & 0.818 & 0.904 & $(0,864 ; 0944)$ & 44.713 & 0.000 \\
\hline
\end{tabular}

The addiction to the Internet (linear, positive medium correlation) shows also good correlation with the appearance of Internet abuse in workplace. The employees who are addicted to the Internet, increasingly abuse the Internet services in the workplace and vice versa. However the other independent variables have shown low correlation. So, it was concluded that in the case of Slovenia employees the organizational climate, relations in the working organization, the Internet company policy and the demographic factors (gender, age, education and sector of work) have no effect on the abuse of Internet services in the workplace. The only difference was found regarding the regions were the employees work. The central region of Slovenia shows higher frequency of Internet abuse compared to the other four regions. Two hypotheses (H2 and $\mathrm{H} 4)$ about the Internet abuse were confirmed. The other two, hypothesis $\mathrm{H} 1$ and $\mathrm{H} 3$ were rejected. The results from the statistical analysis of the manager surveys are presented on Table 5. Hypotheses $\mathrm{H} 1$ and $\mathrm{H} 3$ were confirmed and $\mathrm{H} 2$ was rejected. The lack of AUP may lead to introduction of more severe disciplinary measures as well as the e-monitoring increase the employees' fear of application of more severe disciplinary measures.

Table 5. Verification of the hypotheses from the manager's survey-t-statistics and regression coefficients

\begin{tabular}{ccccccc}
\hline Dependent Variable & Independent Variable & $\mathbf{R}^{2}$ & OR & $\mathbf{( 9 5 \% ~ C I )}$ & $\mathbf{t}$ & $\mathbf{p}$ \\
\hline $\begin{array}{c}\text { Lack of Internet use policy } \\
\text { H1 confirmed } \\
\begin{array}{c}\text { Provision of additional } \\
\text { education of employees }\end{array}\end{array}$ & Disciplinary measures & 0.169 & 0.411 & $(0.226 ; 0.625)$ & 4.234 & 0.000 \\
H2 rejected & Internet abuse & 0.031 & 0.177 & $(-0.029 ; 0.358)$ & 1.685 & 0.095 \\
$\begin{array}{c}\text { Introduction of e-monitoring } \\
\text { H3 confirmed }\end{array}$ & Disciplinary measures & 0.371 & 0.609 & $(0.342 ; 0.603)$ & 7.204 & 0.000 \\
\hline
\end{tabular}

\section{Discussion}

\subsection{General Overview}

Based on the data analysis presented above, a multi-dimensional construct was designed for the factors influencing Internet addiction and Internet abuse, as presented in Figure 1. 


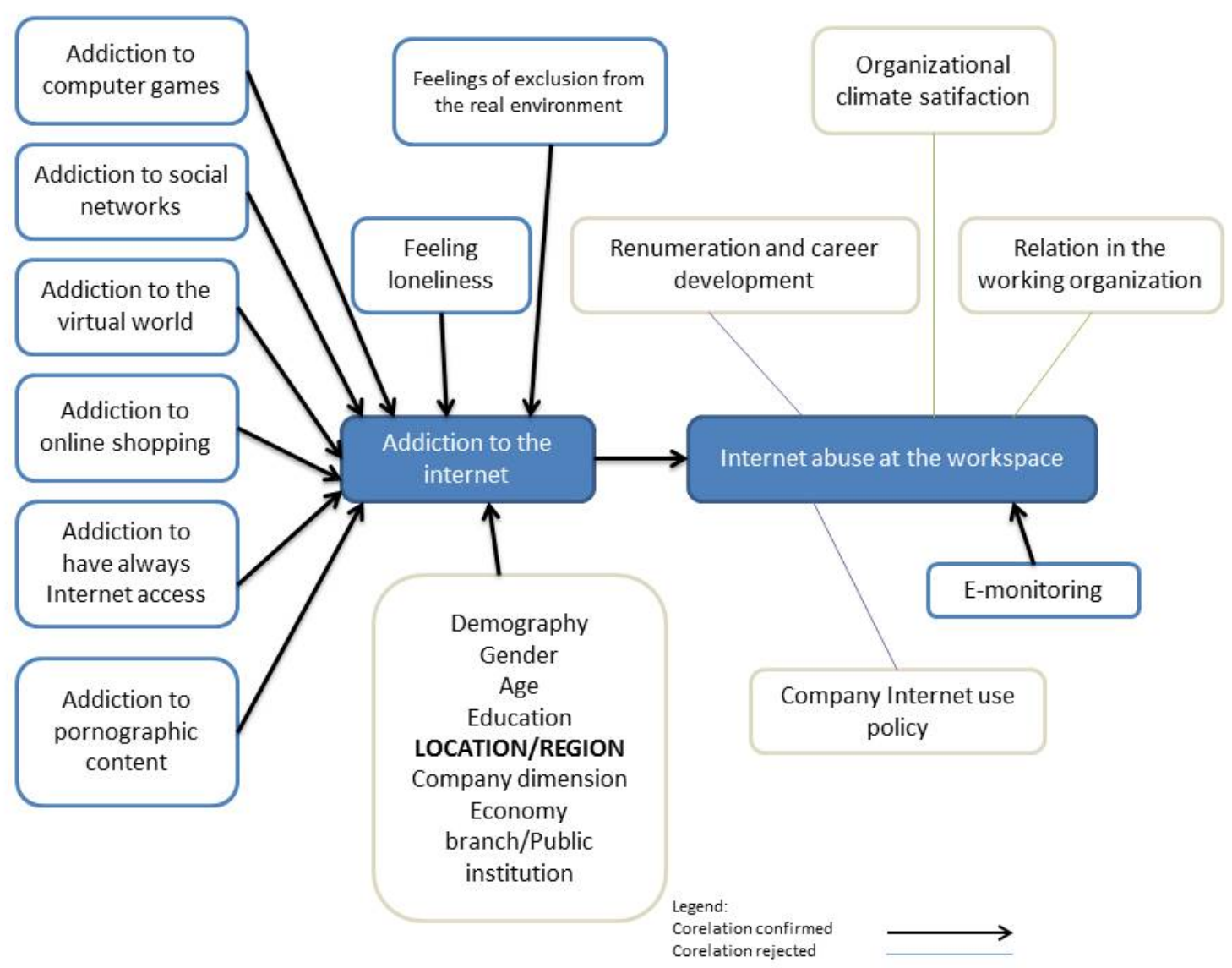

Figure 1. The model of the factor dependencies

The results of the statistical analysis, the values of the correlation coefficient $r$ and the parameter from the regression analysis confirmed some results presented in previous studies (Chen, 2008) namely Internet addiction is strongly correlated to the addiction to several Internet services. Internet-addicted people in Slovenia have similar feeling like being isolated from the real social environment and feeling of loneliness. Addicted people as employees abuse the Internet, as they use it to modulate negative moods and to escape work pressures. They try to improve their moods when they are down, anxious, or socially isolated and consequently change their behaviour. These findings support the claims that Internet abuse is symptomatic and similar to other types of abuse. Intensive on-line shopping, sex addiction or pornography watching are associated with a number of psychological and social relation problems that appear among Internet abusers too, such as social isolation, depression, anxiety and personal disorders. So, more research in this direction would be beneficial as more new explanations may emerge. One of them is the fear of new technologies (Ziyanak, 2014). There are people who are intimidated by new technologies and especially this applies for aged people in aging population in the developed part of the world (Morahan, 2000, 2005). The new technologies are changing lives in a way that was unimaginable a decade ago - for example, it is not always clear now what kind of information will appear and with whom one is socializing. Individualisation of the society is another recognized effect of the new communication technologies. It should be stressed here, that the Internet is no much more addictive or compulsive than watching television, talking on the phone or any other leisure activity. Internet-addicted people in Slovenia are employees that spend more of their working time performing non-work-related actions on the Internet, and this is a risk recognized by the Slovenian managers (Gorenc, 2016). The AUP and disciplinary measures are applied in some of the studied organizations, but most of them are increasingly questionable under the pressure to follow the privacy protection legislation adopted in EU. This study has shown that the applicable AUP is not welcomed by the Slovenian employees. According to the study results, the only factor that may deter Internet abuse in the workplace is the awareness that the employees are under electronic monitoring. A similar effect is expected if the non-acceptance of the AUP by the employees may lead to even more severe disciplinary measures. The study has shown also that the demographic data about gender, age, education and income, or the 
branch of the economic sector or the company dimension, have no significant correlation with the Internet abuse in the workplace. Distinction was noticeable only in the origin of the participants - the employees as the studied sample covered all parts of Slovenia. More abuse occurred in the central region of Slovenia, with its capital Ljubljana. This was easily explained, as this region is the most developed in the country.

\subsection{Managers View of the Problem}

Employees who abuse Internet privileges in the workplace are still a major concern among today's companies and other organizations that rely on modern Internet-based technology for their businesses or processes. An increasing number of companies provide Internet access to more than one half of their employees, and our study has shown that employee Internet abuse is on the rise in Slovenia as well. Managers from a range of companies from the whole country have expressed concerns about this phenomenon and have also undertaken different attempts in the organization to minimize productivity losses resulting from employees' Internet abuse. Most of the interviewed managers declared that they themselves use the Internet in any place where they stay, and that their Internet use is $90 \%$ job-related. They also confirmed that they spent at least three hours a day on the Internet. In the interviews, they were asked about their views and applied approaches in the application of content-filtering tools, granted privileges of Internet use for their employees, and whether there is an implementation of a company's AUP. Another important question was related to the ethical approach used when monitoring Internet use and how severe the applied discipline measures in the case of an employee's Internet abuse were. Information whether their organization is organizing trainings and education about AUP and whether any employees have lost their jobs due to Internet abuse, was collected too. Most of the managers gave positive answers when asked about their decisions to take an ethical approach in implementing Internet use monitoring by informing the employees in advance about the applied measure. The managers' answers have shown that larger companies have already adopted documents defining an AUP but in addition their systems are issuing always warning messages to employees' computers about the consequences of violating the policy. Several companies are also requesting a template to be signed by the employee, indicating his/her consent that the Internet will not be used for private purposes in the workplace. Another finding was that public institutions have implemented, in larger numbers, filtering software that blocks access to Internet hate speech and to sites with banned contents. The AUP was more frequently developed and applied in organizations belonging to the public sector than in the private sector. On the other hand, disciplinary actions in the form of warning messages about excessive Internet use issued to the employee were more frequently applied by privately owned companies than in institutions belonging to the public sector. Despite the fact that many larger organizations are introducing measures to prevent Internet abuse in the workplace, our study has shown that HR managers and legal advisors responsible for company Internet-risk management policies have taken ethical approaches in the provision and implementation of the AUP. The obligation to observe privacy protection in a person's electronic communications, as defined by the EU legal order, was present in most of the cases discussed during the interviews with managers. It was found that the approach reported by the managers was different compared to the practice in the USA (Staple, 1997), where the employees do not have any legal tool available against private employee monitoring, even if it is implemented in a discriminatory fashion without notice. The European legislation offers procedural protections against employers' workplace surveillance of e-mails or other Internet activities, but even in EU, there is a difference in the procedural protections of privacy in communication for public and private employees. The European approach is the strongest where personal information is abused by unlawful monitoring, as privacy is regarded as a fundamental right throughout Europe. However, in the case of employee Internet use, they have an unqualified right to receive notice of their employer's monitoring practices that exist or are introduced in the company. In addition, it should be noted here that in Europe, any use of information obtained by electronic surveillance is illegal if notice is not given to the concerned people. According to the EU Directive on Data Protection and Privacy, employees have the right to be notified of all uses and disclosures of their personal data in the form of collection, transmission and processing.

In any case, a good Acceptable Use Policy defined within the company that will be adopted by the employees should lead to reasonable Internet use and will probably contribute to the occurrence of fewer cases of Internet abuse in the workplace. The AUP should be a written agreement with each employee of the company or institution using personal e-mail and Internet access. The employees should sign the AUP and acknowledge the understanding of its requirements as a prerequisite to gaining password access to the company devices and network. The AUP should indicate that the employer reserves the right to monitor the usage of the internal networks and Internet system, although monitoring of specific content, e.g., personal e-mail, will not occur, except in cases of suspected improper behaviour. 


\section{Conclusion}

\subsection{Limitations of the Study}

At the end some limitations of the performed research should be acknowledged. In web-based studies, it is always shard to see exactly how many of the real effects of addiction and consequently abuse are reflected in the employees' answers, as no sufficient control is possible in selecting the responders who were willing to provide answers. The study certainly differentiates from other carried studies, as different sectors and industries with their employees participated in the e-survey in an EU member state. In addition, for better understanding of the problem face-to-face interviews with HR and IT managers were held with aim to get more light in the subject. In this type of study, the employee's perceptions of Internet use and abuse may also differ because of the kind of work they do, and due to the nature of their workplace which is difficult to be controlled in the survey. However, the answers indicated that in most cases the work performed by the addicted employee is boring. The study has also provided an insight into the approaches taken by the managers in implementing measures that would restrict Internet abuse, without directly exploring and entering more deeply into the privacy concerns of electronic monitoring and other type of surveillance. Most managers have declared an ethical approach in e-monitoring, and they claimed that privileges in the form of a personal user Id and password are given to the employees. Cases of employment dismissal due to Internet abuse were reported as rare.

\subsection{Concluding Remarks}

The concern about Internet abuse has grown as the Internet use has proliferated worldwide at home and at the workplace. Most employees in companies working globally today have access to the Internet in the work place. In the past twenty years, Internet abuse was treated mainly in clinical practice as an addiction, similar to gambling or drug and alcohol abuse that emerge in people with mood disorders and those who are lonely, socially anxious or who use these tools to cope with negative feelings. With the proliferation of Internet use, its abuse appears now as a problem within the work environment in many regions due to the impact that its excessive use has on the company's productivity. The study presented in this paper has confirmed the similarity of addictions to gambling to the dependence on social networks, virtual world and electronic communications. All of them, lead to Internet addiction and consequently to Internet abuse in the workplace. To deter Internet abuse in workplace, the most powerful tool seems to be the employee's awareness of being e-monitored but the application of such tools should be in accordance to the employee privacy protection as defined by the European legislation order. Despite the limitations mentioned above, the study contributes to an understanding of the addictive Internet use behaviour and its correlation with the Internet abuse in the workplace. More studies on Internet addiction and abuse in countries with a different location, culture, population and development level are needed for understanding of these phenomena and provision of inputs for development of better and more exact measurement instruments. Understanding the ethical rules and measures in applying disciplinary steps to deter Internet abuse in the workplace will certainly contribute to the decrease of this phenomenon. The problematic use of Internet in workplace is not only a problem in terms of productivity loss, it address also the possibility of enacting more norms like committing e-crime of some type, including intellectual property theft, money laundering and distribution of offensive materials. For this reason, efforts involved in developing AUPs, adequate training and education despite the current negative attitudes displayed by the employees will certainly deter Internet abuse and force the employees who have little or no control over the time they spend on the Internet to change their behaviour.

\section{Acknowledgments}

This study was supported by the Slovenian National Agency of Research under the grant agreement 106-P0037.

\section{References}

APA (American Psychiatric Association). (1994). Diagnostic and statistical manual of mental disorders (DSM-IV) (4th ed.). Washington, DC: American Psychiatric Association.

Chak, K., \& Leungm, L. (2004). Shyness and Locus of Control as Predictors of Internet Addiction and Internet Use. Cyber Psychology \& Behaviour, 7(5), 559-570. https://doi.org/10.1089/cpb.2004.7.559

Chang, M. K., \& Law, M. P. (2008). Factor structure for Young's Internet Addiction Test: A confirmation Study. Computers in Human Behaviour, 24, 2597-2619. https://doi.org/10.1016/j.chb.2008.03.001

Chen, V. J., Chen, C. C., \& Yang, H. (2008). An empirical evaluation of key factors contributing to internet abuse in the work place. Industrial management and Data, 108(1), 87-105. https://doi.org/10.1108/02635570810844106 
Churchill, G. A., Brown, J. T., \& Suter, T. (2004). Basic marketing Research (5th ed.). Mason Ohio PC Thompson.

Gorenc, M., Jerman-Blažič, B., \& Urnaut, A. G. (2016). Internet addiction-Empirical verification. IIASS, 9(3), 24-32. https://doi.org/10.12959/issn.1855-0541.IIASS-2016-no3-art2

Griffiths, M. (2010). Internet abuse and internet addiction in the work place. The journal of workplace learning, 22(7), 463-471. https://doi.org/10.1108/13665621011071127

Harwood, J., Dooley, J. J., Scott, A. J., \& Joiner, R. (2014). Constantly connected-The effects of smart-devices on mental health. Computers in Human Behaviour, 34, 267-272. https://doi.org/10.1016/j.chb.2014.02.006

Holden, C. (2001). Behavioural' Addictions: Do They Exist? Science, 295(2), 980-982. https://doi.org/10.1126/science.294.5544.980

Internet in Europe 2014, Internet World Stats. (2014). Internet User Statistics \& 2014 Population for the European countries and regions. Retrieved December 21, 2014, from http://www.internetworldstats.com/stats4.htm

Jiang, Q. (2014). Internet addiction among young people in China: Internet connectedness, online gaming, and academic performance decrement. Internet Research, 24(1), 2-20. https://doi.org/10.1108/IntR-01-2013-0004

Kayiş, A. R., Satici, S. A., Yilmaz, M. F., Şimşek, D., Ceyhan, E., \& Bakioğlu, F. (2016). Big five-personality trait and internet addiction: A meta-analytic review. Computers in Human Behavior, 63, 35-40. https://doi.org/10.1016/j.chb.2016.05.012

Kitzinger, J., \& Barbour, R. (1999). Developing Focus Group Research: Politics. In Theory and Practice. SAGE P.C, London.

Li, D., Zhang, W., Li, X., Zhou, Y., Zhao, L., \& Wang, Y. (2016). Stressful life events and adolescent Internet addiction: The mediating role of psychological needs satisfaction and the moderating role of coping style. Computers in Human Behavior, 63, 408-415. https://doi.org/10.1016/j.chb.2016.05.070

Li, W., Garland, E. L., \& Howard, M. O. (2014). Family factors in Internet addiction among Chinese youth: A review of English-and Chinese-language studies. Computers in Human Behaviour, 31, 393-411. https://doi.org/10.1016/j.chb.2013.11.004

Morahan-Martin, J. (2005). Addiction? Disorder? Symtom? Alternative Explanations? Social Science Computer Review, 23(1), 39-48. https://doi.org/10.1177/0894439304271533

Morahan-Martin, J., \& Schumacher, P. (2000). Incidence and correlates of pathological Internet use among college students. Computers in Human Behaviour, 16(1), 13-29. https://doi.org/10.1016/S0747-5632(99)00049-7

Neging, P., Musa, R., \& Wahab, R. (2014). Unlocking the Determinants of Pathological Internet Use (PIU) among Urban Millennial Teens. Procedia-Social and Behavioural Sciences, 130, 21-27. https://doi.org/10.1016/j.sbspro.2014.04.003

Noll, J. G., Shenk, C. E., Barnes, J. E., \& Haralson, K. J. (2013). Association of Maltreatment with High-Risk Internet Behaviors and Offline Encounters. Paediatrics, 131(2), e510-e517. https://doi.org/10.1542/peds.2012-1281

Rustad, M., \& Paulsson, S. (2005). Monitoring employee email and, usage: Avoiding the omniscient, electronic, sweatshop: Insight from Europe. Journal of Labour and Employment Law, 7(4), 829-904.

Selwyn, N. (2008). A safe haven for misbehaving? An investigation of online misbehaviour among university students-Social Science Computer Review. Science Computer Review, 26(4), 446-465. https://doi.org/10.1177/0894439307313515

Seymour, L., \& Nadasen, K. (2007). Web access for IT staff: A developing world perspective on web abuse. The Electronic Library, 25(5), 543-557. https://doi.org/10.1108/02640470710829532

Shaffer, H. (1996). Understanding the means of objects of addiction: Technology, the Internet, and Gambling. Journal of Gambling Studies, 12, 461-469. https://doi.org/10.1007/BF01539189

Shapira, N. A., Goldsmith, T. D., Keck, P. E. Jr., Khosla, U. M., \& McElroy, S. L. (2000). Psychiatric features of individuals with problematic internet use. Journal of Affective Disorders, 57(1-3), 267-272. https://doi.org/10.1016/S0165-0327(99)00107-X 
Snapshot, S. (2008). Employer Computer and Internet abuse statistics. Retrieved from http://www.snapshotspy.com/employee-computer-abuse-statistics.htm

Staples, W. G. (1997). The Culture of Surveillance; Discipline and Social Control in the United States (pp. 155). St. Martin's Press.

Staples, W. G. (2013). Everyday surveillance: Vigilance and visibility in postmodern life. Rowman \& Littlefield, 255 .

Treuer, T., Fabian, Z., \& Furred, J. (2001). Internet addiction associated with features of impulse control disorder: Is it a real psychiatric disorder? Journal of Affective Disorders, 66(2-3), 283. https://doi.org/10.1016/S0165-0327(00)00261-5

Websense Inc. (2000). Survey on Internet Misuse in the Workplace.

Whang, L. S., Lee, S., \& Chang, G. (2003). Internet over-users psychological profiles: A behaviour sampling analysis on internet addiction. Cyberpsychology and Behaviour, 6(2), 143-150. https://doi.org/10.1089/109493103321640338

Young, K. S. (1996). Psychology of computer use: XL. Addictive use of the Internet: A case that breaks the stereotype. Psychological Reports, 79(3), 899-902. https://doi.org/10.2466/pr0.1996.79.3.899

Young, K. S. (1998). Internet addiction: The emergence of a new clinical disorder. Cyberpsychology and Behaviour, 1(3), 237-244. https://doi.org/10.1089/cpb.1998.1.237

Young, K. S., \& Case, C. J. (2004). Internet abuse in the workplace: New trends in risk management. Cyber Psychology and Behaviour, 7(1), 105-111. https://doi.org/10.1089/109493104322820174

Ziyanak, S. (2014). Examining the Impact of Technology in the Formation of Deviance and Social Control. International Journal of Humanities and Social Science, 5(1), 207-2010.

\section{Appendix}

Appendix 1. Manager sample and survey questions

\begin{tabular}{ccc}
\hline \multicolumn{2}{c}{ Sample of 31 managers } & Percentage \\
\hline \multirow{2}{*}{ Gender } & male & $33.3 \%$ \\
& female & $66.7 \%$ \\
Up to 30 & $10.0 \%$ \\
Age & $30-40$ & $60.0 \%$ \\
& $40-50$ & $23.3 \%$ \\
Education & 50 and more & $6.7 \%$ \\
& High school & $13.3 \%$ \\
& College & $6.7 \%$ \\
Company size & University & $53.3 \%$ \\
& Master degree & $26.7 \%$ \\
& Small & $26.7 \%$ \\
& Middle & $20.0 \%$ \\
Economic sector & Large & $53.3 \%$ \\
& Public & $46.7 \%$ \\
& Private & $53.3 \%$ \\
& East & $20.0 \%$ \\
& Central & $60.0 \%$ \\
& West & $20.0 \%$ \\
\hline \multirow{2}{*}{ Region } & &
\end{tabular}


Q1:

Q1a Do you monitor employees at work?

Q1b Do you follow moral and ethical principles in the implementation of control?

Q1c Do you use information technology to control the workplace?

Q1d Do you have Internet filters on the computers-and therefore blocked access to illicit, offensive Internet sites that are not work-related?

Q1e Has anyone been given a notice because he was abusing Internet services in the workplace?

Q2:

Q2a Have Internet privileges ever been taken from someone due to the abuse of Internet services in the workplace?

Q2b Do you use any special software for monitoring all websites that are visited and used by employees in your company?

Q2c Do you have in your company any particular computer software in each computer that monitors the browsing of Internet services at a specific time?

Q2d Do you record typing in your company?

Q2e Do you have a computer integrated monitoring of electronic files in your company (e.g., to find out if the employees transfer a file that is not work-related)?

Q3:

Q3a Have you ever given anyone a warning because they were abusing Internet services in the workplace?

Q3b Does the company store and read employees' e-mails?

Q3c Do you have any special software for monitoring e-mails in your company?

Q3d Have you ever restricted access to Internet services for some employees in your company?

Q3e Have you ever limited the use of Internet services for employees' personal use in their free time or after working hours?

Q4:

Q4a Do your employees who have access to Internet services in the workplace have the user names for their computers?

Q4b Does your company measure the time of connecting and disconnecting to Internet services on the company's computers?

Q4c Do you have cameras in your company for monitoring what employees are doing on the computers?

Q4d Do you have a company's policy on the proper use of internet services "Company Internet Use Policy" to prevent employees from abusing Internet services in the workplace?

Q5:

Q5a Do you have in your company a written policy/guide stating that Internet services are to be used only for business purposes?

Q5b Have you ever given employees any form to sign stating that they would refrain from visiting offensive Internet sites during working hours?

Q5c Are your employees informed about the correct use of Internet services by means of a "Company Internet Use Policy" when they log into their computers?

Q5d Does your company organize seminars and meetings of employees for new and old employees in order to inform them about the proper use of Internet services in the workplace?

\section{Copyrights}

Copyright for this article is retained by the author(s), with first publication rights granted to the journal.

This is an open-access article distributed under the terms and conditions of the Creative Commons Attribution license (http://creativecommons.org/licenses/by/4.0/). 